chiefs of service and pay them adequately to devote a large measure of time to the hospital.

A word about the small general hospitals: I recognize that much admirable work is done in these institutions. I believe, however, that sometimes too little thought is given to the community need when such a hospital is started. Often a hospital could be erected at a central point which would serve several towns and be able to command better work than could several smaller institutions in the various towns. There is a tendency in some of the smaller hospitals for members of the staff to attempt surgery for which they have had no adequate training. In some places this has been a crying scandal. Medical associations are now proposing to license surgeons. This will help a great deal, but there must be developed a public sentiment which will make ignorant surgery impossible. A surgeon of small experience must learn that it is no disgrace to admit that a given patient's chances are better in the hands of another man and tranfer the invalid to the metropolitan hospital, if feasible.

Well authenticated report comes to me that in some hospitals in certain sections of the country the standards of deportment, decorum, and, in some instances, even decency, are low. The relations of staff and nurses are altogether too intimate. No hospital with low standards in this particular can ever permanently flourish or do good work. I wonder if this has anything to do with the difficulty of some of these hospitals in getting nurses? To any of you who know that I am justified in making these charges, I leave the answer to this question.

Too many small hospitals are started without adequate provision for their support. The result is a constant struggle and a probable attempt to make the unfortunate nurse in charge carry a greater burden than anyone should be asked to carry, both in hours of work and responsibility.

We should all use our influence against the starting of a hospital until it has been clearly shown that it is necessary; that the location suggested best meets the need; that there is adequate support in evidence, and that its conduct is in the hands of those whose ideals are high and whose methods are practical.

In 1905, when this association last met in Boston, I well remember hearing an honored superintendent of long experience urge that meetings should be held once in three years, because all the subjects of interest to hospital superintendents had been pretty thoroughly discussed. This was just before any adequate realization of the expanding work of the modern hospital and the responsibilities of its administrator. In selecting topics for my words to you, I have been embarrassed not by the paucity of interesting subjects, but by their multiplicity.

I thank you for the honor which you have conferred upon me in making me your president, and it is my most sincere wish that this meeting may be productive of benefit to the hospital world.

\section{(19rininal Artirlex.}

\section{ATROPHIC RHINITIS WITH OZENA. ITS ETIOLOGY AND SURGICAL TREAT- MENT.*}

FRAXCIS P. EMERSON, M.D., BOSTON.

Assistant Aural Surgeon, Massachusetts Charitable Eye and Ear Infirmary; Instructor Laryngology and Otology, Harvard Graduate School of Medicine.

\section{INTRODUCTION.}

From the discussion of atrophic rhinitis with ozena, as found in the literature, it is evident that special investigators are particularly interested in two methods of procedure in the study of the cause and treatment of this disease.

First, in an attempt to isolate a specific organism and establish a method of treatment based on such findings, and second, in looking upon the symptom complex as due to pus-producing organisms, causing multiple foci that are amenable to the recognized surgical principles of drainage and cleanliness.

The difficulties encountered by an investigation along the first procedure are due to the results of decomposition and secondary infection, which give rise to an innumerable bacterial flora and interferes with an attempt to determine which particular one is the active organism in the disease.

Renewed interest has been awakened of late by the work of Abel and his experiments with the Bacillus Mucosus Ozena. This painstaking work has led others to attempt to substantiate his claims. An excellent article, among others, appeared last year in this country, by Cobb and Nagle. This phase of the subject has already in previous years engaged the attention of the members of the profession, notably Lowenberg, Pesand, Gradenigo, Dreyfuss, Loeb, Ambi, Brindell, Gruenwald, Hajek, Marano, Abel and others, but without any definite results.

In the second method of procedure, where the symptom complex is considered as due to an attenuated infection with multiple foci, secondary to a pan-sinusitis, this would suggest that the original infection is not followed by an essential or primary atrophic process, acting as an intermediate step, but that the sinuses are invaded directly by a pus-producing organism. While it is conceivable that foetor and erusting might be produced by the breaking down of soft tissue, bone necrosis and defective drainage, with the resulting secondary infection, yet we know that certain pus-producing organisms

* Read at the annual meeting of the Laryngological, Rhinological and Otological Society at Washington, May, 1913. 
by themselves are capable of causing a thin, others a thick, secretion, and still others may cause foetor and crusting. In this sense a specific organism might be necessary to produce ozena, but not necessarily have, as its primary manifestation an atrophic tissue change. If we accept the latter view, which the writer believes is true, we can with advantage continue to search for a specific organism and at the same time, perfect our surgical technic, because purulent retention within non elastic walls requires free drainage, as a pre-requisite to cure, whatever the infective agent might be.

\section{THEORIES.}

From the earliest medical records to the present time, many theories have been advanced as to the etiology of ozena, but none of them have had a considerable following, among men of eminence. For a review of this literature, you are referred to the excellent article by Sendziak in the Annals of Otology, Rhinology and Laryngology for 1907.

That tuberculosis and syphilis cause a certain number of cases is conceded, but the researches of Sobernheim, Eisenbohr and Alexander by the aid of the Wassermann test, showed that syphilis, the disease most suspected as a cause of ozena, was responsible for relatively only a small percentage.

Bosworth's theory of a preceding purulent rhinitis, with no sinus involvement as a cause of ozena in later life, has been questioned by the researches of Pearce at the Boston City Hospital and of Pearce and Winne at the Albany Bender I Jaboratory, who showed conclusively that the sinuses are often invaded by a pus-producing organism in the course of the infectious diseases as early as the second year. Is it not also the experience of all rhinologists, with their present better knowledge of sinus infections, that a primary purulent rhinitis is a thing of the past? It is always secondary to some focus of infection in the epipharynx or hollow spaces.

Theories based on the shape of the face, as being a cause are less often referred to today with our more definite pathology on which to base a diagnosis.

The Herd theory of a sinus disease as a cause of ozena, has had such able exponents as Greunwald, Hajek, Loehnberg, Michel and not a few among the members of this society, although this theory has not been generally accepted; yet the writer brings this phase of a much discussed subject before you today again, because of his belief that the rapid advance in our knowledge of and ability to cure sinus diseases, has opened new possibilities in the study of the etiology and cure of ozena, even granting a specific organism. In the past, when treating these focal troubles intranasally, even if we agreed as to its etiology, yet our knowledge of the surgical technic of sinus disease has advanced sufficiently to make it possible to adopt a common method of thorough exenteration of involved cells. This would in turn lead us to some definite agreement for or against a focal infection, as being the chief underlying cause of this disgusting affection.

\section{PERSONAI، WORK.}

It is for this purpose that I venture to offer the results of the following surgical procedure, after briefly stating the grounds, which in my opinion implicate the accessory sinuses, without there being a true atrophic process.

First, the writer has never seen a case of a so-called atrophic rhinitis, that was not relieved by thorough drainage, instead of being made worse, as would be the case, if trauma and increased air space were added to a genuine atrophic mucosa.

Second, the crust formation and foetor when unilateral, are always on the wide side, where they have apparently been preceded by a compensatory hypertrophy of the second turbinate, due to the deviated septum. This enlarged turbinate would in turn interfere with the proper drainage of a subsequent sinus infection.

Third, the discharge of pus over a mucous surface, in a long standing case, is in the writer's experience always accompanied by a glazed appearance of the mucosa, dryness and an exudate, a low grade catarrhal process, and not a true atrophic process. That this is not a true atrophy is shown by the return of function of the mucous surface with the establishment of free drainage and the cure of the underlying focal infection. This is often seen on the posterior pharyngeal wall in cases of chronic sinusitis of the sphenoid cavity, or posterior ethmoid cells.

Fourth, radical surgery with the object of establishing free drainage, lessens the tendency to crust formation, instead of increasing it. The lessening of crust formation is in proportion to the thoroughness with which the affected cells are drained. This is followed by a purulent or muco-purulent discharge, until the diseased surface is made healthy, by topical applications and cleanliness. Nowhere in the body does nature tolerate so much abuse as in the nasal chambers, if we provide free exit for the secretions.

Fifth, ethmoid disease, the writer believes to be the most constant of the infectious processes in the nasal chambers. As a suppurative ethmoiditis it is easily recognized. On the other hand, there are inflammatory processes of the ethmoid cells which are less active, or where the drainage is better, in which case, they are characterized by serious infiltrations, dilatation of the capillaries, with the mucous membrane dry and red; and if seen after the process has been going on a certain length of time, there is found covering the mucous surface an exudate which is made up of dead epithelium, pus mucus 
and blood. These seem to be the steps and the macroscopic appearances clinically of a certain type of catarrhal ethmoiditis. 'This type of an inflammatory process, where it fails to undergo resolution, passes into a chronic condition, which the writer has repeatedly noticed, was spoken of by many clinicians as atrophic rhinitis. Since these cases of so-called atrophic rhinitis get well under improved drainage, the question would therefore arise, whether the clinical term of "atrophic rhinitis" is a misnomer or the pathological understanding of atrophy is incorrect. To the writer it is inconceivable that a true atrophy with destruction of the glandular elements and an increase in the connective tissue stroma, should resume its function clinically, as is the case of the mucous membranes of the nasal chambers, where a free exit for the secretions is provided. Such cases untreated may continue indefinitely, but when the ostia become obstructed by inflammatory changes, and drainage is interfered with, a subsequent active infection may take place resulting in a suppurative ethmoiditis.

Sixth, the general systemic symptoms, such as pallor, loss of weight, muscular weakness, gastric and other symptoms, are a sequel rather than a predisposing cause of the local condition. These symptoms are found to improve with diminished absorption, as the local condition is relieved.

Seventh, the writer's cases of ozena have shown the morbid process more uniformly to be in the ethmoid and spherroid sinuses. Next in frequency have been the ethmoid, sphenoid and frontal, and last ethmoid, sphenoid and antrum.

The preceding observations were further strengthened by the classical work of Gruenwald on nasal suppuration and the report of cases by Michel, Lowenberg, Hajek, Mayer, Beck, Theissen and others, although in the beginning of this work, the cases were tedious and necessarily difficult to cure, owing to the haphazard way individual cells were attacked at that time and their proneness to relapse with re-infection, yet the results during the last four years have grown increasingly more satisfactory with added experience and a better technic. I wish to emphasize right here that the successful results in the treatment of these cases of so-called atrophic rhinitis with ozena depends absolutely upon the careful after-treatment, which is fully as important as the thorough surgical exenteration. Regular and painstaking care must be exercised until all the affected surface is brought into a healthy condition; and even then for a long time we have a membrane with low vitality, easily re-infected and functionally disturbed.

\section{GENERAL DESCRIPTION OF CASES.}

The clinical cases fall into two general classes, one, the typical cases of Fraenkel with crusting, foetor, anosmia, necrosis and sloughing of the soft tissue, and second the atypical cases in which foetor and crusting may be absent and where the diagnosis of attenuated sinus infection might be more an open question. Contrary to the established facts in the treatment of diseases, the older the stage of this disease, the easier it is to cure. This is in perfect harmony with the sinus theory of the etiology of ozena, owing to the fact that in the third stage, where the infection is less active, the ostia open and the drainage more or less perfect, due to the necrosis and the sloughing of the soft tissue, there is left a smooth bony surface, and therefore the cure is relatively easy.

In the second stage, although earlier in the disease, with the mucous membrane boggy, drainage blocked, and the entire surface covered with a thick, firm crust, the problem is increasingly difficult.

The element of foetor has not seemed to the writer to indicate that a case would present any additional obstacle to healing, for the reason that the odor may be due to a particular organism, not necessarily more virulent or more intractable to overcome than those with little or no odor. In fact the only serious problem is an anatomical one. In those cases where the cell; are developed in the floor of the frontal sinus or out over the orbit, it is obvious that drainage must be obtained by extranasal methods. If we assume that drainage is essential, then we must admit that a certain per cent. of cases of ozena presenting these anatomical peculiarities cannot be cured by any intranasal procedures, whether these are along medical or surgical lines. These variations in development have been pointed out by Shambaugh in an excellent article entitled: "The Construction of the Ethmoid Labyrinth," in the Annals of Otology, Rhinology and Laryngology, Vol. 16, 1907.

We approach our surgical procedure then with the understanding that,

First, for anatomical reasons all cases cannot be cured intranasally.

Second, that when functionally cured the previously infected surface is prone to relapse, due to re-infection.

Third, that only constant attention to drainage, the removal of polypi, topical applications and cleanliness following radical exenteration will avail in any case. Given these conditions, the writer believes that as large a percentage of cases of ozena can be brought to a successful issue as we could expect to cure intranasally, cases of undoubted pan-sinusitis.

\section{SURGICAL TECHNIC.}

The first step consists in anesthetizing the patient in a reclining position. $\mathrm{He}$ is then placed in a chair and then the nasal mucosa is adrenalized. The sphenoidal opening is next located with a probe and if not easily accessible, part of the second turbinate is removed, in order that we may take away enough of the anterior 
sphenoidol wall, so that the enlarged sphenoid opening can easily be recognized, when the land marks have been removed. Next the method of Mosher is employed to systematically exenterate under direct vision the ethmoid labyrinth. With the head tipped back the agger nasi cell is located a little above and in front of the attachment of the second turbinal, corresponding to the rounded eminence on the outer nasal wall. This is found with a curette, by first feeling for the hard surface of the superior maxillary process and then working toward its posterior margin until you break through the thin outer wall of the cell, which corresponds to a large cavity lying at the floor of the naso-frontal duct. It is now important to bring the head forward, so that it is at right angles to the body. The curette is then turned so that it faces the nares, away from the orbit. With a lateral to and fro motion the inner cell walls and partitions can with a little practice be easily broken down by the sense of touch, back to the posterior ethmoid cell. The point here which the writer wishes to emphasize is, that the curette is not to be used to remove the lining membrane, but as an instrument to break down the bony partitions and nasal wall of the cells. This leaves the second turbinate turned down and attached by a narrow base which can be wholly removed by the nasal scissors or forceps in a few minutes. We next pack the operative field with strips of gauze wet in a solution of adrenalin 1-3000. We can now work on the opposite side, where our original operative procedure is duplicated and the field tamponed. The gauze in the first side is then removed, the enlarged sphenoidal opening sought, and its remaining anterior wall is then removed up to the posterior ethmoid cell. The field is then gone over by introducing the little finger into the nares in order that we may detect any irregular bony projections or margins of cells that may interfere with drainage. All granulations and polypi should be removed without destroying the entire mucous lining. The patient is then returned to bed without any nasal packing.

\section{AFTER-TREATMENT.}

First, mechanically remove all crusts gently to avoid bleeding. If the drainage is good after the first week or ten days, these will cease to form and the discharge will have become mucopurulent.

Second, after the first week remove all polypi, that may appear. These will tend to return for several weeks.

Third, use the Bier suction apparatus after first washing out the sphenoid eavity with a cannula. Watch especially the sphenoid opening at its margin where it tends to granulate rapidly and obstruct drainage, as pointed out by Hajek. Touch the margin with silver nitrate, or trichloracetic acid, until it remains permanently open as the result of cicatrization.
Fourth, make the surface dry by gentle pressure and after the first week apply a 4 to $8 \%$ solution of silver nitrate, especially to the sphenoid eavity itself and over all unhealthy areas wherever found.

Fifth, if the patients live at any distance, allow an alkaline wash to be sniffed twice daily, from the hand or a table spoon. The surplus water should then be blown.from the nares without taking hold of the nose on account of the danger of back pressure in the Eustachian tubes.

Sixth, do not allow a water spray of any kind to be used. For four weeks the patient should be seen two or three times a week, then for four weeks more once a week, and after that at irregular intervals until discharged. Remember to caution the patient that an acute infection will bring on a relapse which should be attended to at once. This usually means only a few treatments, after the acute infection subsides.

\section{GENERAL SUMMARY.}

The interest of the profession in the etiology of ozena seems from the literature to be centered upon two methods of procedure.

First, in an attempt to isolate a specific organism, and second, in looking upon the symptom complex as due to pus-producing organisms, causing multiple foci.

The difficulty in isolating a specific organism, arises from the innumerable bacterial flora, resulting from decomposition and secondary infection.

The second procedure does not admit an essential or primary atrophy as an intermediate step in the disease.

Theoretically, a specific pus-producing organism might cause foetor and crusting, without a true atrophic process. That tuberculosis and syphilis are the underlying cause of ozena, except in a small per cent. of cases is not probable.

Bosworth's theory of a preceding purulent rhinitis in infancy without a sinus infection is questioned. The post-mortem reports of Pearce and Winne show sinus involvement as early as the second year in the course of the infectious diseases.

More definite pathology has led to the abandonment of many former etiological theories. The rapid advance in our knowledge of and ability to cure accessory sinus disease makes it now possible to adopt a more uniform surgical technic for their exenteration. This should show more definitely the relationship of sinus infection to ozena.

What seems to be an atrophic process is always improved by drainage.

\section{SUMMARY CONCLUDED.}

A sinusitis frequently develops in the following manner. A septal deviation is followed by 
a compensatory hypertrophy of the second turbinate with a resulting catarrhal ethmoiditis. "This hypertrophy and catarrhal inflammation so interfere with drainage that a subsequent infection by a pus-producing organism makes a sinusitis probable.

A chronic catarrhal inflammation accompanied by an exudate is frequently spoken of as an atrophic process. The return of function with improved drainings shows that it is not a true atrophy. Radical surgery, by establishing better drainage, lessens the tendency to crust formation. Is atrophic rhinitis then a misnomer?

The general systemic symptoms are secondary. The writer's cases have shown the morbid process more often to be in the ethmoid and sphenoid sinuses; next often in the ethmoid, sphenoid and frontal, and last the ethmoid, sphenoid and antrum.

There are two types of clinical cases, one the typical cases of Fraenkel and the other the atypical cases, without foetor and crusting. The atypical cases are less open to question in regard to sinus involvement. The third stage of the disease is more easy to cure. The after-treatment is as important as the surgical exenteration. Foeter does not indicate a more intractable case. The serious obstacle to cure arises from an abnormality in the development of the bony cells. When such abnormal cells are present, certain cases of ozena are incurable by any intranasal method. All cases are easily re-infected, but respond readily to local applications, if the drainage is good.

\section{CLINICAL CASES.}

CASE 1. Mrs. H. C., 39 years. Born in Norway. Married.

Diagnosis. Bilateral atrophic rhinitis with chronic ethmoiditis and sphenoiditis and a traumatic perforation of the septum.

Operation. Radical exenteration of the ethmoid labyrinth and sphenoid sinus on the right side, leaving the left as a check.

History. F. H. negative. Pain general over the head and face for five years. Profuse discharge from the nose for two years. Has had several previous nasal operations.

Examination. The entire nasal septum is destroyed to the ethmoid plate, leaving a large central perforation. Both inferior turbinates are shrunken and covered with crusts. Part of the middle turbinate remains. There is a large opening on either side of the cribriform plate. An x-ray shows double ethmoid clouding. The left frontal region is unsatisfactory. Thick scabs are general over both sides and underneath there is a foetid purulent secretion.

Operation. 9. 16. 11. Dr. Emerson.

Owing to previous operations the land marks are destroyed. There is some difficulty in locating the agger nasi cell. The ethmoid region between the posterior ethmoid cell and the anterior is one solid bony mass, with the wall too thick to penetrate safely. The anterior and posterior region was thoroughly opened and the remains of the turbinate removed.
Operation. Feb. 12, 1912. Dr. Emerson.

Exenteration of the left ethmoid labyrinth and sphenoid under ether. Polypi in left posterior ethmoid cell removed. Partial remains of the right anterior sphenoidal wall removed.

Result. March 23. The right side has been free from crusts and odor for two weeks. The left side has some free pus especially in the region of the naso-frontal duct and cribriform plate. Some headache on the left side.

Note. This case was followed at the writer's office for some weeks until he was convinced that there was trouble in the left frontal sinus. This was uncertain from the $\mathrm{x}$-ray plate. A Killian operation was then performed, which showed that the ethmoid cells extended out of the orbit and that there was a large cell in the crista galli. The frontal sinus was full of granulations and considerable pus was seen coming from the cell in the crista galli as well as from the sinus. Such a case could not be drained intranasally.

Result. The right nose has been clear for months. The left has a few drops of clear pus coming from the frontal sinus.

CASE 2. A. H. Born in Ireland. 26 years. Domestic. Single.

Diagnosis. Bilateral atrophic rhinitis with chronic ethmoiditis and sphenoiditis.

History. F. H. One brother has bi-lateral ethmoiditis. Mother and one sister has goitre. No specific history. Measles at nine years. Frequent colds and discharge from the nose for five years. Pleurisy four years ago for a week. Occasional headaches. Odor from the nose has made it difficult for the patient to retain her position as a domestic. She is not strong and tires easily.

Examination. Patient poorly nourished. Cheeks flushed and tongue coated. Alae flattened. Septum deflected to the left. Whole outer nasal wall on both sides covered with a thick crust that can be removed with nasal forceps en masse. Under this a bleeding surface and free stinking pus.

Report from the Boston Consumptives Home. Lungs and sputum negative.

Operation. Exenteration of ethmoid cells and anterior sphenoidal walls.

Result. Patient was treated at intervals for a year as the ethmoid region was exenterated at intervals under local anesthesia. For two years the patient has been entirely well with no odor or dryness and the mucous membrane is clean. The sphenoidal openings are large and clean. She has gained twenty pounds and has used no wash for a year.

Note. During the last year the patient has been treated only twice following an acute infection. This patient was one of the most marked cases of ozena; she now shows a perfectly clean nose without the use of any wash.

Case 3. A. E., 32 years. Born in Russia. Grocer. Married.

Diagnosis. Bilateral atrophic rhinitis with chronic ethmoiditis and sphenoiditis.

Operation. Radical exenteration of the ethmoid cells and anterior wall of the sphenoid under ether. History. F. H. negative. Patient referred for an examination for a possible focal infection as a cause of his endocarditis. There is crusting and discharge from the nose with loss of smell. Duration seven years. He has been to several hospitals, 
and was there told that his disease was incurable. $\mathrm{He}$ is weak and finds it difficult to do his work.

Examination. Crusting over both outer walls of the nares, with very offensive discharge underneath. The second turbinates are shrunken. A large quantity of free pus is seen in the right middle meatus. The bridge of the nose is somewhat depressed. The septum is deflected to the left at the upper third. The right sphenoid cavity is very large, the left nearly obliterated.

Result. The tendency to crusting stopped in two weeks. There was persistent discharge from the region of the right sphenoid until it was discovered that there was a partition in the sinus with a narrow vertical ostia close to the septum, leading into the main cavity, which had not been opened. The partition was removed and the cavity irrigated; then treated with silver nitrate 8 per cent. Further trouble was experienced by the tendency of the margin of the anterior wall to fill in with granulations. Finally by the use of silver nitrate and trichloracetic acid to the margin, this was overcome and the cavity remained permanently open, and the discharge ceased.

CaSE 4. H. H. Shoemaker. Married. Born Russia. 31 years.

Diagnosis. Bilateral ethmoiditis and sphenoiditis with ozena. L-O. M. S. Ch.

History. Severe headaches for 8 years. The writer had performed a radical mastoid on the left side, and in doing the dressings the foul sour odor from the nose was very marked.

Examination. Both nares contain a considerable amount of foul pus with crusting. The middle turbinates are boggy and myxomatous at their anterior ends. Anosmia complete.

Operation. Oct. 8, 1912. Both ethmoid labyrinths were exenterated from before backward under ether. Both anterior walls of the sphenoids were removed and the two cavities connected.

Oct. 20, 1912. Nose clean and no odor.

Oct. 31. 1912. Patient discharged from the hospital and treatment continued at the writer's office. Nov. 10, 1912. Discharged.

Result. The patient moved to Michigan and was treated there four times as the nose was not completely healed.

April 22, 1913. Examination by the writer showed the nares free from crusts or discharge. Both sphenoid cavities are widely opened.

Case 5. A. M. Born in Nova Scotia. 44 years. Married. Furniture mover.

Diagnosis. Bilateral atrophic rhinitis with chronic ethmoiditis and sphenoiditis.

Operation. Exenteration of the ethmoid cells and the anterior walls of the sphenoids. Local anesthesia.

History. F. H. negative. No specific history obtained. Malaria 14 years ago. Several attacks of otitis media. Dryness of the nose and crusting with loss of sense of smell for 20 years.

Examination. The middle turbinals are covered with dry crusts and also the post nasal space. The nasal cavities are wide. The turbinals are atrophied on both sides including the middle and inferior. The mucous membrane is pale and dry. There are several erosions on the septum.

Result. This case was one representing the socalled terminal stage of ozena and responded quickly to operative measures. For four years there has been no nasal symptoms.

Case 6. November 18, 1908. C. N. C. Irish American. Born in Ireland. 53 years. Married. News agent.

Diagnosis. Bilateral atrophic rhinitis with chronic ethmoiditis and sphenoiditis.

Operation. Radical exenteration of ethmoid and sphenoid sinuses under ether.

History. F. H. negative. No specific or tubercular history obtained. Catarrh for ten years with nasal obstruction and loss of smell. Colds often. Hacking cough. Post nasal discharge. Patient spends a long time each morning trying to get his nose free from crusts. Indigestion with chronic bronchitis and bronchorrhea for 10 years. Aprosexia and neurasthenia marked. Odor pronounced.

Examination. Face pale and pinched. Nose small and alae flattened. Septum to the right. Inferior turbinates atrophied. Right middle turbinate large and covered with dry secretion. The left middle turbinate shows myxomatous degeneration and there is a polyp between it and the outer wall. Erosion on the septum. Pharynx atrophic, glazed and dry.

Result. Following a radical exenteration the crusts and odor disappeared and for two years there have been no nasal symptoms.

Case 7. M. F. Born Boston. Irish American. 20 years. Single. Female. Brushmaker.

Diagnosis. Atrophic rhinitis with chronic bilateral sinusitis of ethmoid and sphenoid.

History. F. H. negative. No specific or tubercular history. Pneumonia 10 years ago. For four years the patient had had headaches on rising, especially over the right eye. Colds often. She has been under constant treatment at various hospitals for four years. Sense of smell lost; occasional epistaxis. Odor marked.

\section{$S$. $P$. General condition fairly good.}

Examination. Alae flattened; septum is deflected to the left. Both inferior turbinates are covered with crusts. Right middle turbinate very large. Much muco-pus in the middle meatus. Mucous membrane, where it is not covered with crusts, is dry and the nose obstructed. Pharynx dry.

Operation. Exenteration of ethmoid cells and anterior wall of the sphenoids under local anesthesia. Os planum on the right side is partially destroyed.

Result. Patient has been seen at frequent intervals for a year. For the last two years she has been entirely well with no nasal symptoms.

Case 8. G. B. American. Born in Vermont. 25 years. Married. Advertising manager for a machine company.

Diagnosis. Atrophic rhinitis with bilateral sinusitis of ethmoid and sphenoid.

Operation. Exenteration of ethmoid and sphenoid sinuses, under ether.

History. F. H. negative. No specific history obtained. Frequent colds. Loss of smell. Nose obstructed and dry for ten years. Scarlet fever as a child. Pneumonia ten years ago. General pressure symptoms over the entire head. Muscular weakness. Aprosexia. Odor marked.

Examination. General condition poor. Face pale. Alae flattened and dilated. Odor marked. 
Septum deviated to the right with a horizontal ridge and posterior spur. Both outer walls of the nares are covered with crusts, which bleed on removal. Middle turbinals swollen and ulcerated. Much muco-purulent discharge especially in the posterior nares. Pharynx dry and glazed.

Result. This case was much improved, but on account of the fact that he lived in an adjoining state, and could not be seen except at long intervals, he is far from being cured. Since treatment was stopped there has been no crusting or odor, but there is considerable purulent discharge, which the patient can remove by using the nasal wash.

\section{Conclusions.}

The illustrative cases of ozena here presented are only a few out of a large number seen by the writer, during the last ten years. The study of these and similar cases has led to the belief that ozena is the sequel of a focal infection.

Clinically the course of events is as follows: a septal deviation causes a compensatory hypertrophy of the middle turbinal. This is followed by a chronic catarrhal ethmoiditis which interferes with drainage to such an extent that a subsequent active infection results in a sinusitis.

The foetor and crusting are probably due to the direct action of a specific pus-producing organism on the tissues, without any preceding true atrophic process.

The difficulty in establishing free drainage, where there is an abnormal anatomical development of the bony cells, makes the cure of certain cases of ozena impossible with any intranasal procedure.

Whatever aid bacteriology may give us in curing this disease, must follow the free drainage of all foci of infection.

\section{BIBLIOGRAPHY,}

Alexander, A.: Serodiagnostische Untersuchungen zur Frage der Beziehungen twischen Ozaena und Syphilis. Ztschr. f. Laryngol. $\cdot u$. Rhinol., Wurzb., 1909, vol. i, pp. 669-684.

Alexander, A.: Ueber das Wesen der Ozaena. Arch. f. Laryngol u. Rhinol., Berlin, 1909, vol. xxii, pp. 260-348.

Baumgarten, E.: Ueber die Frueformen der Ozaena. Arch. f. Laryngol. u. Rhinol., Berlin, 1909, vol. xxii, pp. 492-497.

Betti, A.: Rev. Hebd. de Laryngol., etc., Nov. 12, 94. Some Observations in Ozena. 1904

Dobell: The Formation of the Secretion in Ozena. Arch. Laryng., vol. Xv, No. 1,1903 .

Dionisio: Recueil de memoires sur la Laryngol., la rhinol, et otol. No. 2, 1904. Radiation in the Treatment of Ozena.

Compaird: Pure Atrophic Ozena of the Eustachian Tube and Middle Ear. Rev. Hebdom de Laryngol. de Otol. et de Rhinol., ct. $15,1910$.

Eckstein: Dauerheilung einer Ozaena durch Hartparafininjek tion. Berlin. Klin. Wochenschrift, 1911, vol. xviii, pp. 401-403.

Eisenbohr. Die Wassermansche Reaktion bei Ozaena. Ztschr. f Ohrenh., Wiesbaden, 1909, vol. vi, pp. 401.410.

Frese: Ueber die Beziehungen der Syphilis zur Ozaena. Arch. f

Larvngol. u. Rhinol., Berlin, 1908, vol. xx, pp. 459-474.

Freudenthal: Is Atrophic Rhinitis always Ontochthonous? An-

nals of Otol. Rhinol and Laryngol., June, 1903.

Gruenwald u. A. Waldrann: Studien tiber den bakteriellen An-

teil an der Produktion des Ozaenae-Syndroms. Centralbl. f. Bak-

teriol., I. Abt., Jena, 1911, vol. x.; Orig. 337-350.

Goswin-Ziehgraf: 'Ueber Behandlung mit Ozaenolyt. Klin.

Therap. Woch., Berlin, 1910, vol. xvii, p. 1226.

Guamaccia, Prof.: (Catane) Rev, Hebd. de Laryngol., etc, Oct. 15, 1904. The Paraffin Treatment of Atrophic Rhinitis. Laryngoscope, p. 70 .

Hutter, F.: Zur Paraffin-Therapie der Ozaena. Arch. f. Laryn gol. u. Rhinol., Berlin, 1910-11, vol. xxiv, pp. 189-198.

Harris: Atrophic Rhinitis Depending upon Ethmoiditis with External Operation on the Ethmoid. Laryngoscope, 1909, p. 548.

Hollinger: No Terra Incognito. Chicago. Laryngoscope, 1909.

Hopman: Sicheres u. Unsicheres tiber Ozaena. Monatschr.

Ohrenh., 1907, xol. xi, pp. 255-273.

Iglauer: The Treatment of Atrophic Rhinitis by Oro-Naso and Canula. Published in full in the Laryngoscope, 1906, vol. xv, p. 833 .
Kahn: Treatment of Ozena by the Submucous Injection of Paraffin into the Nasal Chamber with a Review of other Methods. Laryngoscope, 1911, p. 737.

Kyle: Atrophic Rhinitis with Ozena. The Pathology of. 1908, laryngoscope, p. 423.

Lautman: Ist die Genuine Ozaena eine Infektionskrankheit? tschr. Laryngologie, Rhinol., Wurzburg, 1909, vol. $i$, pp. 421-429. Large: Atrophic Rhinitis.' Laryngoscope, 1909, p. 230.

Myles: Atrophic Rhinitis. Including Ozena. The Treatment of. Laryngoscope, 1908 , p. 425.

Mueller: Ueber die Behandlung der Ozaena Simplex mith Protargol. Zentralzlatt f. d. ges. Therap., Wien u. Berlin, 1908, vol. xxvi, pp. 449.452.

Moeller: Atmokausis bei Ozaena. Verhandl. d. Ver. Deutscher Laryngol., Würzburg, 1910 , pp. 317-322.

Richards: Atrophic Rhinitis. The Treatment of. Laryngoscope, 1908 , p. 429.

Rice: Atrophic Rhinitis and Ozena. Laryngoscope, 1908, p. 435 Sobernheim: Wassermannsche Komplementbindungsmethode und Ozaena. Arch. f. Laryngol. u. Rhinol., Berlin, 1909, vol. xxii, pp. 1.9.

Schmidt: Zur Therapie der Ozaena. Gurgeln mit Geschlosse Mund. München. Med. Wochenschr., 1908, vol. v, p 1239.

Sobernheim: Ozaena und Syphilis. Arch. f. Laryngol. u. Rhinol. erlin, 1909, vol. xxii, 430.435.

Steiner: Development of the Study of Ozena. Oroosi hetil. Budapest, 1908, vol. ii, pp. 622-624.

Steiner: Zur Weiterentwicklung der Lehre von der Ozaena. arch. f. Laryngol. u. Rhinol., Berlin, 1908, vol. xxi, pp. 282-290. Stiel : Ueber Behandlung der Ozaena mit Dionin. Therap. Monatsschr., Berlin, 1907, vol. xxi, pp. 633-635.

Schoenemann: Weitere Beiträge zur Pathogenese und Therapie der Ozaena. Verhandl. d. Ver. deut. Laryngol., Wurzburg, 1909, pp. 100-102.

Theissen: A Consideration of the Herd Theory, as an Etiological Factor in Ozaena. Laryngoscope, 1908, p. 417.

\section{SPINAL ABSCESSES.}

BY JAMES K. YOUNG, M.D., PHILADELPHLA,

\section{Associate Professor of Orthopedic Surgery, University of}

From time immemorial, a large collection of fluid in any part of the spine, as a result of destructive changes, and slow in its progress, has always been regarded as a "cold" abscess. The exact character of these collections was unknown to surgeons prior to the time of Percival Pott (1779), their tuberculous nature, however, was suspected by a coterie of distinguished French surgeons as early as 1825 and for several years succeeding, but the real pathological character of these abscess contents was not scientifically demonstrated until the memorable labors of Koch were given to the world in 1882 and still further corroborated and elaborated by the more recent advances in the field of bacteriology. For a long time, the view obtained that all cold abscesses were tuberculous in character; at the present time, however, this deduction has been proved fallacious, and we are enabled to recognize the presence of many organisms in association with spinal abscess besides the tubercle bacillus.

The abscess may be secondary to infection from the staphylococcus, the streptococcus, gonorrhea, typhoid fever, rheumatism, actinomycosis $^{1}$ and very rarely perhaps from syphilis; as well as those instances associated with osteoarthritis and arthritis deformans. Among the rarer varieties are those occasionally seen in conjunction with tabes dorsalis, and rarely in gout.

With spinal abseesses there is usually little constitutional disturbance, a slight rise of evening temperature, mild rigors and perspiration. 